\title{
Trajectories of Behavioural Disturbances Across Dementia Types
}

\author{
Alexandra B. Linds, Alana B. Kirstein, Morris Freedman, \\ Nicolaas P.L.G. Verhoeff, Uri Wolf, Tiffany W. Chow
}

\begin{abstract}
Objective: To replicate a previous finding that the trajectory of the Neuropsychiatric Inventory (NPI) shifts in the sixth year of behavioural variant frontotemporal dementia (bvFTD). We evaluated longitudinal tracking with both the Frontal Behavioural Inventory (FBI) and NPI, comparing bvFTD against other dementias. Methods: Chart reviews over two to five years for patients with bvFTD ( $\mathrm{n}=30$ ), primary progressive aphasia (PPA, $n=13)$ and Alzheimer's disease $(\mathrm{AD}, \mathrm{n}=118)$ at an urban Canadian tertiary clinic specializing in dementia. Linear regressions of the longitudinal data tested predictors of annualized rates of change (ROC) in NPI and FBI total and subscales for apathy and disinhibition among dementia groups. Results: The mode of the overall sample for the most advanced duration of illness observed was 5 years, with the median at 7 years. We did not find a crescendo-decrescendo pattern in scores although, for bvFTD and AD, high initial scores correlated with ensuing downward ROCs on the NPI and FBI. Educational level showed an influence on disinhibition ROCs. The FBI was no more revealing than the NPI for apathy and disinhibition scores in these dementias. Conclusions: A cognitive reserve effect on behavioural disturbance was supported but it may take longer than our 4 years of observing the clinical sample to record inflection points in the behavioural and psychiatric symptoms seen in bvFTD. The current data only imply that both apathy and disinhibition will diminish over the course of dementia.
\end{abstract}

RÉSUMÉ: Trajectoire des troubles du comportement dans différents types de démences. Objectif: Le but de l'étude était de reproduire les constatations antérieures concernant les changements de trajectoire notés à l'Inventaire neuropsychiatrique (INP) au cours de la sixième année d'évolution de la variante comportementale de la démence fronto-temporale (vcDFT). Nous avons examiné le suivi longitudinal de patients effectué au moyen de l'Inventaire du comportement frontal (ICF) et de l'INP et comparé les résultats de ces tests dans la vcDFT par rapport aux autres démences. Méthode: Nous avons revu les dossiers de patients atteints de $\operatorname{vcDFT}(\mathrm{n}=30)$, d'aphasie progressive primaire $(\mathrm{APP}, \mathrm{n}=13)$ et de maladie d'Alzheimer $($ MA, $\mathrm{n}=118)$ fréquentant une clinique de soins tertiaires d'un centre urbain canadien spécialisé dans la démence. Nous avons examiné les facteurs de prédiction des taux annualisés de changement (TAC) dans ces différents groupes de patients au moyen de l'analyse de régression linéaire des données longitudinales de l'INP et de l'ICF global ainsi que des sous échelles pour l'apathie et la désinhibition. Résultats: La valeur modale de l'échantillon total pour la durée la plus longue de la maladie observée était de 5 ans et la médiane était de 7 ans. Nous n'avons pas constaté de patron en crescendo-décrescendo dans les scores, bien que pour la vcDFT et la MA des scores initiaux élevés étaient corrélés à un TAC à la baisse à l'INP et à l'ICF. Le niveau de scolarité avait une influence sur le TAC de la désinhibition. L'ICF n'était pas plus performant que l'INP en ce qui concerne l'apathie et la désinhibition dans ces démences. Conclusions: Les données sont en faveur d'un effet de la réserve cognitive sur les troubles du comportement, mais il faudrait sans doute une période d'observation clinique plus longue que 4 ans pour noter des points d'inflexion dans les symptômes comportementaux et psychiatriques observés dans la vcDFT. Les données actuelles laissent seulement soupçonner que l'apathie et la désinhibition diminuent au cours de l'évolution de la démence.

Keywords: Alzheimer's, apathy, behavioural and psychiatric symptoms of dementia, behavioural variant frontotemporal dementia, disease progression, disinhibition, duration of illness, longitudinal study, primary progressive aphasia

doi:10.1017/cjn.2015.266

Can J Neurol Sci. 2015; 42: 389-394

\section{INTRODUCTION}

The behavioural and psychiatric symptoms (BPSD) in behavioural variant frontotemporal dementia (bvFTD) consist of apathy, loss of empathy, inappropriate responses, and hyperactive behaviours. ${ }^{1}$ Primary progressive aphasia (PPA) patients can also manifest these behaviours over time. ${ }^{2,3}$ We have previously hypothesized that the pattern of evolution in BPSD for bvFTD shows initially significant disinhibition, which ultimately gives way to apathy and lack of engagement. ${ }^{4}$

The BPSD that frequently appear in Alzheimer's disease (AD) are dysphoria, agitation, and anxiety; ${ }^{5}$ apathy is also seen in $\mathrm{AD}$, at a lower frequency than in bvFTD. ${ }^{6}$
The Frontal Behavioural Inventory $(\mathrm{FBI})^{7}$ assesses disinhibited behaviours and deficit behaviours (apathy). While FBI scores for the bvFTD group were not available for our previous work based on data from the University of California at

From the Faculty of Health Sciences (AK), Wilfrid Laurier University, Waterloo; Rotman Research Institute of Baycrest (AL, MF, NV,TC); Baycrest Department of Psychiatry (UW); Baycrest Department of Neurology (MF), Baycrest Health Sciences; Faculty of Medicine (MF,TC), Faculty of Psychiatry (NV,TC), University of Toronto; Department of Neurology (MF), Mt. Sinai, Toronto, Ontario, Canada.

Received August 20, 2014. Final Revisions Submitted June 2, 2015.

Correspondence to: Tiffany Chow, Rotman Research Institute, Baycrest Health Sciences, 3560 Bathurst Street, Toronto, ON, Canada; M6A 2E. Email: aloha.drchow@gmail.com. 
San Francisco, the bvFTD group did demonstrate an initial increase in total Neuropsychiatric Inventory (NPI) scores and subsequent decline at the sixth year of illness. ${ }^{4}$

In the present study, we examined a new longitudinal dataset collected at a Canadian tertiary care clinic to replicate the change in BPSD trajectory with both the NPI and FBI in bvFTD, PPA and AD.

\section{Materials ANd Methods}

\section{Standard protocol approvals, registrations, and patient consents}

Formal and informal caregivers participated in an annual clinical telephone follow-up by summer research students at the Sam and Ida Ross Memory Clinic at Baycrest Health Sciences. Procedures for collecting the dataset were approved by the Research Ethics Board at Baycrest. Verbal informed consent to publish the anonymized data was obtained from informants during the telephone interviews.

\section{Participant Series}

Calls were made to informants for patients identified by billing or appointment records as having been evaluated, diagnosed, and treated at the Clinic in each prior year (April $1-$ March 31). Of the 412 patients meeting clinical diagnostic criteria for bvFTD, PPA, or $\mathrm{AD}, 172$ had informants available and willing to participate at least twice in the annual telephone follow-up. Thirty of these participants had bvFTD, 13 had PPA (including progressive non-fluent aphasia and semantic dementia) by Neary criteria, ${ }^{8}$ and 118 had AD (including possible $\mathrm{AD}$, probable $\mathrm{AD}$, and $\mathrm{AD}$ with cerebral vascular disease) by McKhann Criteria. ${ }^{9}$ Fifteen patients with corticobasal syndrome (CBS) and five patients with progressive supranuclear palsy were included as bvFTD or PPA, if they met the diagnostic criteria for those latter diagnoses. Corticobasal degeneration and PSP are often the underlying pathology for PPA or bvFTD, respectively. ${ }^{10,11}$ One of these CBS patients was autopsyconfirmed as corticobasal ganglionic degeneration. Patients with mixed dementia (AD and vascular dementia) were excluded.

Demographic information for the sample is summarized in Table 1. A majority (64\%) of the patients had two sets of scores available, while the remainder had three $(29 \%)$, four $(6 \%)$ or five sets $(1 \%)$.

\section{Behavioural Assessments}

Four clinical inventory assessments were administered to caregivers serially. These included: the Functional Rating Scale (FRS), ${ }^{10}$ the Clinical Dementia Rating Scale modified for FTD (CDR-FTLD), ${ }^{11,12}$ the FBI and the NPI. ${ }^{13}$ We used the baseline
FRS and CDR-FTLD scores to characterize the sample (see Table 1); the two latter inventories were the determinants of the rates of annual change. Specifically, the FBI assesses deficit behaviours such as apathy, aspontaneity, indifference, inflexibility, personal neglect, disorganization, inattention, loss of insight, logopenia, verbal apraxia, comprehension deficit and alien hand/ apraxia; and disinhibited behaviours such as perseverations/ obsessions, irritability, excessive jocularity, impulsivity, restlessness, social inappropriateness, aggression, hyperorality, hypersexuality, utilization behaviour and incontinence.

The NPI assesses the frequency and severity of delusions, hallucinations, agitation/aggression, depression, anxiety, euphoria, apathy, disinhibition, irritability, aberrant motor behaviours and sleep and eating disorders. $^{13}$

Information on disease onset was determined by using the informant-reported year of earliest persistently abnormal clinical feature regarding language, behavioural comportment and personality, memory or executive functioning, as elicited by a physician or nurse during any clinical visit.

Some informants were not available to participate at annual intervals but were included with serial scores spanning longer than two years $(27 \%)$.

\section{Statistical analysis}

We conducted statistical analyses on SPSS version 20.0 (IBM Corporation, N.Y). Linear regression analyses were used to determine the annualized rates of change (ROC) for the FBI and NPI total and sub-scores for each patient over three to five year epochs. For those with two instances, an average duration was used as the annual rate of change. In order to identify an inflection point, we re-created four binary variables from the prior study ${ }^{4}$ to indicate whether the first assessment took place before or after four, five, six, or seven years into illness. We used linear regression with forward entry of these four duration-related variables to ascertain the most likely predictor for annualized ROC for the behavioural inventories, with post-hoc exploration of whether the ROC before or after a cutoff duration emulated an inflection point. Post-hoc analyses included visualization on scatter plots with examinations of $\mathrm{R}^{2}$ values and independent samples t-tests.

A multivariate regression sought other predictors of the annualized ROC in the NPI and FBI total scores. Potential predictor variables in the analysis included the duration of illness at first case report form, education and the gender and relationship of informant to participant; age at onset and initial behavioural

Table 1: Sample Demographics

\begin{tabular}{|c|c|c|c|}
\hline Dementia Diagnosis & $\operatorname{bvFTD}(n=30)$ & PPA $(n=13)$ & $\mathrm{AD}(\mathrm{n}=118)$ \\
\hline$\%$ Women & $40 \%$ & $46.2 \%$ & $59.3 \%$ \\
\hline Age (years) at onset, mean (SD) & $58.80(7.93)$ & $58.46(9.79)$ & $72.84(10.50)$ \\
\hline Duration of illness (years) at initial assessment, mean (SD) & $6.27(3.24)$ & $4.92(2.84)$ & $6.14(3.37)$ \\
\hline Initial FRS total score, mean (SD) & $29.30(5.82)$ & $24.40(6.36)$ & $24.78(7.44)$ \\
\hline Initial CDR-FTLD sum of boxes score, mean (SD) & $14.1(5.10)$ & $9.40(5.11)$ & $10.35(5.69)$ \\
\hline
\end{tabular}

AD: Alzheimer's disease; bvFTD: behavioural variant frontotemporal dementia; CDR-FTLD: Clinical Dementia Rating Scale modified for FTD; FRS: Functional Rating Scale; PPA: primary progressive aphasia; SD: Standard deviation. 
inventory scores, which had determined NPI ROC in bvFTD and $\mathrm{AD}$ in the previous study, ${ }^{4}$ were also included.

Furthermore, we used the opportunity to compare the NPI and the FBI for correlations to duration of illness for all three types of dementia. Because no inflection point was found, this aspect of posthoc analysis entailed linear regression using the duration of illness as the dependent variable, raw total and sub-scale scores of the NPI and FBI as the independent variables (i.e., at least two data points per participant per inventory score).

\section{RESUltS}

As expected for early-onset dementias, ${ }^{14,15}$ participants with bvFTD and PPA were younger than AD patients $(\mathrm{p}<0.001)$ (see Table 1). Although the median most recent durations of illness were seven to eight years for the three groups, the modes were much shorter for bvFTD (six years), PPA (four years), and AD (five years).

Scatter plots of apathy subscale scores against disinhibition subscale scores revealed the simultaneous occurrence of both types of behavioural disturbance (see Figure 1). Only the AD group had statistically significant bivariate correlations and these were neither inverse nor strongly positive: FBI-apathy x FBIdisinhibition $r=0.39 \quad(p<0.001)$ and NPI-apathy $x$ NPIdisinhibition $r=0.22(p=0.02)$.

The first level of regression analysis revealed no significant epochs for bvFTD ROC on the NPI. Annualized ROC for the FBI and FBI-apathy scores were related to observations beginning before versus after six and seven years duration of bvFTD (see Table 2), yet the respective ROC for the duration subgroups of the sample above did not show crescendo-decrescendo trajectories. Post-hoc independent samples t-tests only supported a significant difference in FBI-apathy annualized ROC observed in the first six years of illness (increasing at 6.23 points per year \pm SD 5.04), as opposed to other participants observed later in their courses of illness still to increase at a much lower ROC $(0.02$ points per year $\pm 6.76, \mathrm{t}=2.52, \mathrm{p}=0.02$ ).

Other predictors revealed in the multivariate regression analyses included some initial inventory scores and education. Only the initial NPI-apathy score predicted the annualized ROC on this item (unstandardized $\beta$ coefficient $=-0.44$, SE 0.14, $p=0.005$ ); lower initial NPI-apathy scores predicted increases in apathy and vice versa, as shown in Figure 2.

Education was a significant predictor for the ROC on the FBI-disinhibition subscale (unstandardized $\beta$ coefficient $=-0.54$, SE $0.23, \mathrm{p}=0.03$ ) but not the ROC on the total FBI score. In other words, escalating disinhibition on the FBI was related to lower educational levels, and a decrease in disinhibition was appreciated among bvFTD participants with higher levels of education (see Figure 3).

Linear regression for the best inventory correlates with duration of bvFTD favored neither the NPI nor the FBI above the other. As shown above, indices from either of the two inventories can be descriptive of bvFTD progression. Post-hoc Pearson's bivariate correlations found that FBI-apathy correlated significantly with duration of illness (see Table 3 ).

There were no inflections in ROC on the FBI or NPI among participants with PPA, nor were the demographic variables predictive of ROC. Neither behavioural inventory was superior for following PPA duration of illness per linear regression, but the FBI total $(r=0.512, p=0.005)$ and its sub-scale scores (apathy:

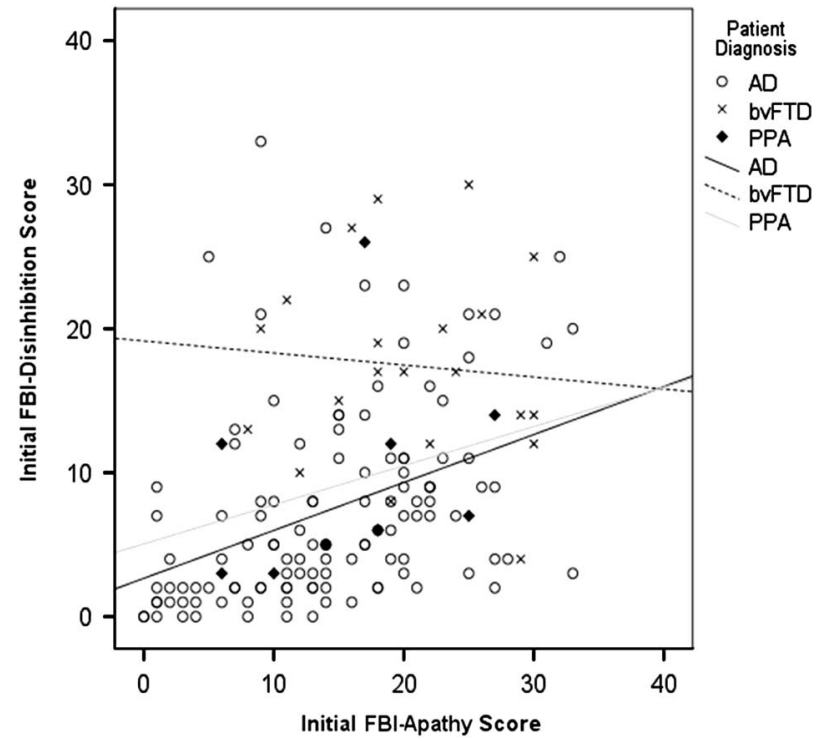

Figure 1: Apathy and disinhibition occur simultaneously across all three dementia groups. Initial apathy and disinhibition scores on the FBI are plotted. Participants with AD had $r=0.39(p<0.001)$ for these scores; bvFTD and PPA $r$ values had $p$ values $>0.05$.

AD: Alzheimer's disease; bvFTD: behavioural variant frontotemporal dementia; FBI: Frontal Behavioural Inventory; PPA: primary progressive aphasia.

Table 2: Linear regression for before and after various durations of bvFTD

\begin{tabular}{|c|c|c|c|c|}
\hline $\begin{array}{l}\text { Dependent } \\
\text { Variable = Total FBI } \\
\text { ROC }\end{array}$ & $\begin{array}{l}\text { Unstandardized } \\
\text { Beta Coefficient }\end{array}$ & $\begin{array}{l}\text { Standard } \\
\text { Error }\end{array}$ & $t$ Value & $\begin{array}{c}P \\
\text { Value }\end{array}$ \\
\hline $\begin{array}{l}\text { Pre-post } 6 \text { years } \\
\text { duration }\end{array}$ & -25.85 & 11.50 & -2.25 & 0.037 \\
\hline $\begin{array}{l}\text { Pre-post } 7 \text { years } \\
\text { duration }\end{array}$ & 32.06 & 10.84 & 2.96 & 0.008 \\
\hline Constant & 1.90 & 5.94 & 0.320 & 0.750 \\
\hline \multicolumn{5}{|l|}{$\begin{array}{l}\text { Dependent } \\
\text { Variable = FBI- } \\
\text { apathy ROC }\end{array}$} \\
\hline $\begin{array}{l}\text { Pre-post } 6 \text { years } \\
\text { duration }\end{array}$ & -23.80 & 4.61 & -5.16 & $<0.001$ \\
\hline $\begin{array}{l}\text { Pre-post } 7 \text { years } \\
\text { duration }\end{array}$ & 20.02 & 4.35 & 4.60 & $<0.001$ \\
\hline Constant & 3.17 & 2.38 & 1.33 & 0.200 \\
\hline
\end{tabular}

bvFTD: behavioural variant frontotemporal dementia; FBI: Frontal Behavioural Inventory; ROC: rate of change.

$\mathrm{r}=0.401, \mathrm{p}=0.034$; disinhibition: $\mathrm{r}=0.494, \mathrm{p}=0.008)$ and not NPI scores were significant correlates with duration of illness.

There were no NPI or FBI inflections for AD patients.

The second level of regression analysis for AD revealed education and initial scores as predictors of annualized ROC. Education predicted disinhibition as measured on the NPI (unstandardized $\beta$ coefficient $=-0.06$, SE 0.03, $\mathrm{p}=0.03$ ), not the FBI for AD, but the $\mathrm{R}^{2}$ value was almost neglible at 0.04 . While disinhibition on the FBI 


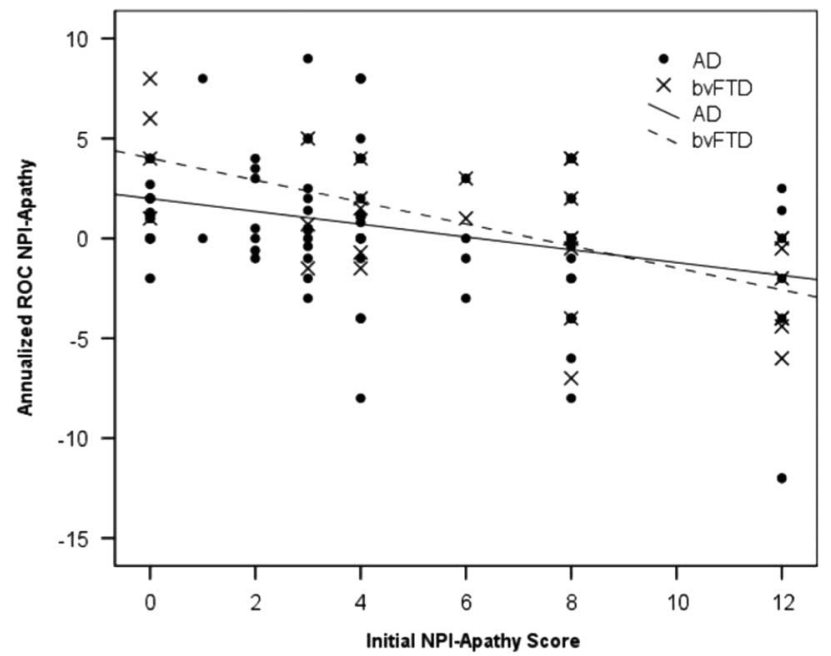

Figure 2: Scatter plot showing initial NPI-apathy subscale scores versus the annualized rate of change on the NPI-apathy subscale for bvFTD and $A D$.

AD: Alzheimer's disease; bvFTD: behavioural variant frontotemporal dementia; NPI: Neuropsychiatric Inventory; ROC: rate of change.

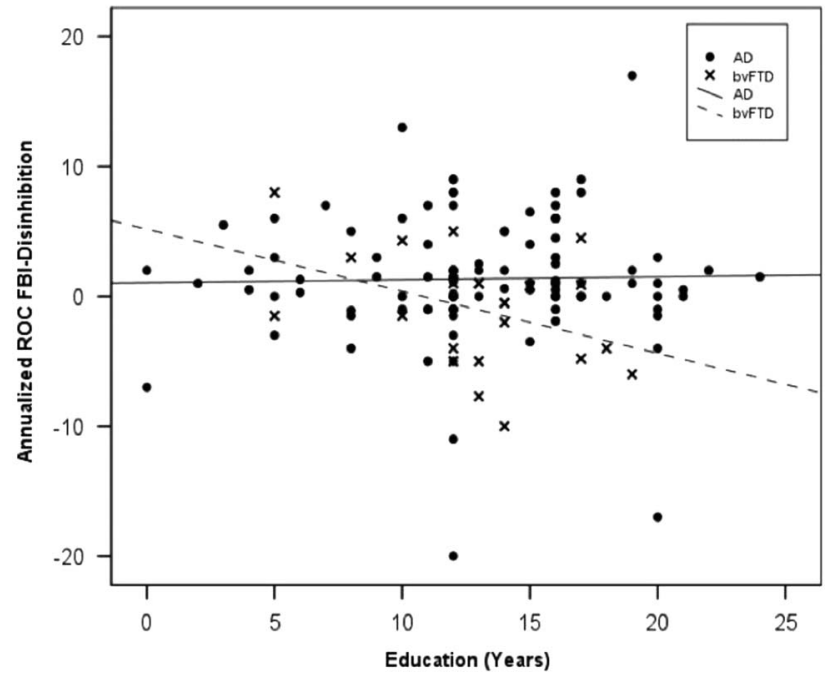

Figure 3: Scatter plot showing the educational level versus the annualized ROC on the FBI-disinhibition subscale in bvFTD versus $A D$. $A D$ : Alzheimer's disease; bvFTD: behavioural variant frontotemporal dementia; FBI: Frontal Behavioural Inventory; ROC: rate of change

was not predicted by education, the initial FBI-disinhibition score showed unstandardized $\beta$ coefficient $=-0.32$, SE $0.07, \mathrm{p}<0.001$ for the FBI-disinhibition ROC (see Figure 4). Participants who presented with high initial FBI disinhibition scores (severe behavioural disturbance) tended to show a lessening of disinhibition over time.

Similar to bvFTD above, the initial NPI-apathy score predicted the NPI-apathy ROC, in the same inverse relationship ROC (unstandardized $\beta$ coefficient $=-0.34$, SE $0.10, p=0.001$, see Figure 2).

As with bvFTD, the NPI was not superior to the FBI in a linear regression for duration of AD. All NPI and FBI scores showed
Table 3: Statistically significant Pearson bivariate correlations with duration of illness ( $r, p$ values)

\begin{tabular}{l|c|c|c}
\hline & $\begin{array}{c}\text { Behavioural } \\
\text { Variant FTD }\end{array}$ & $\begin{array}{c}\text { Alzheimer's } \\
\text { disease }\end{array}$ & $\begin{array}{c}\text { Primary Progressive } \\
\text { Aphasia }\end{array}$ \\
\hline FBI & $\mathrm{n} / \mathrm{a}$ & 0.32 & 0.51 \\
\hline FBI-Apathy & 0.42 & $<0.0001$ & 0.005 \\
\hline & 0.001 & 0.319 & 0.40 \\
\hline $\begin{array}{l}\text { FBI- } \\
\text { Disinhibition }\end{array}$ & $\mathrm{n} / \mathrm{a}$ & $<0.0001$ & 0.03 \\
\hline & & 0.24 & 0.49 \\
\hline NPI Total & $\mathrm{n} / \mathrm{a}$ & 0.0 .0001 & 0.008 \\
\hline & & 0.001 & $\mathrm{n} / \mathrm{a}$ \\
\hline NPI-Apathy & $\mathrm{n} / \mathrm{a}$ & 0.20 & $\mathrm{n} / \mathrm{a}$ \\
\hline & & 0.001 & \\
\hline
\end{tabular}

FBI: Frontal Behavioural Inventory; n/a: not applicable; NPI: Neuropsychiatric Inventory; FTD: frontotemporal dementia

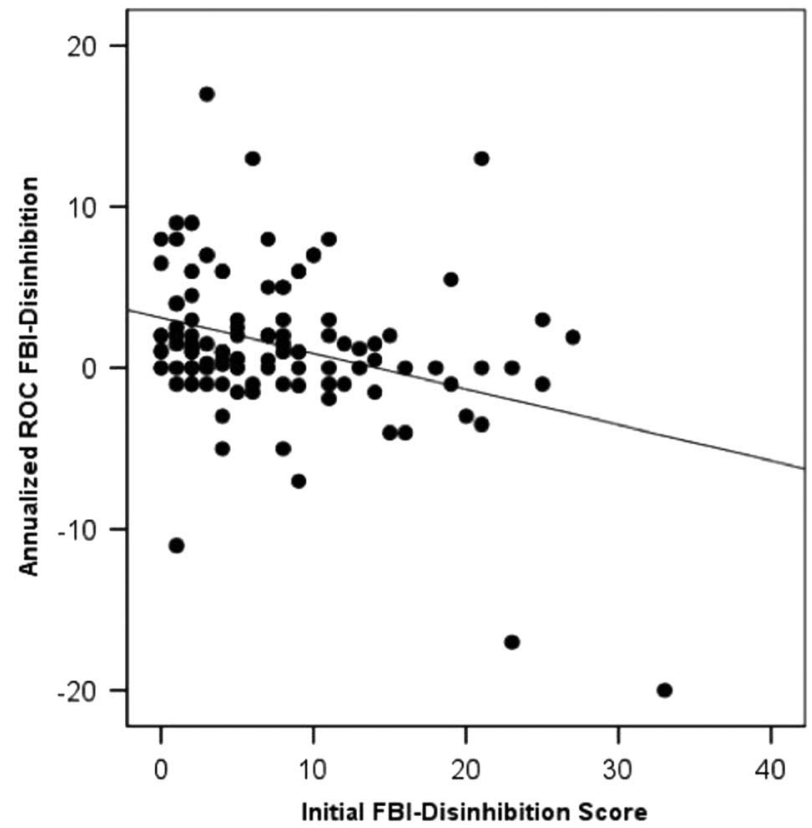

Figure 4: Scatter plot showing initial FBI-disinhibition scores versus the annualized ROC on the FBI-disinhibition subscale for $A D$. AD: Alzheimer's disease; FBI: Frontal Behavioural Inventory; ROC: rate of change.

significant correlations with duration of AD by Pearson bivariate correlation $(p<0.01)$, except NPI-disinhibition.

\section{DISCUSSION}

The purpose of this study was to compare the evolution of BPSD in patients with bvFTD, PPA and AD using longitudinal FBI and NPI data. We were unable to replicate our prior study's identification of a six-year inflection point in BPSD for bvFTD. ${ }^{4}$ 
The current sample differed from the previous bvFTD sample $(n=45)$ in two ways that may account for the disparity in results. First, the current sample $(n=30)$ was two-thirds the size of the prior sample. It is possible that our sample was too small to power the analysis. Perhaps more relevant however, is that our study observed participants who were still closer to onset of illness than ending it, which implies that in another few years the Baycrest sample may manifest the crescendo-decrescendo in disinhibition. We may have missed any switched directions in ROC in participants whom we only captured after their sixth year of illness.

We had not expected to see educational levels correlate with disinhibition ROC in bvFTD (per FBI) and in AD (per NPI). However, higher education may have allowed patients to better compensate for brain pathology through a cognitive reserve mechanism. ${ }^{16}$ Individuals with higher education in this study showed more mild ROC in disinhibition than those with lower education. ${ }^{17}$ Higher education is a correlate of neural plasticity. ${ }^{18}$ The usual context for discussion of cognitive reserve is its protective effect against clinical signs of dementia despite the presence of plaques, neurofibrillary tangles and cerebrovascular disease. ${ }^{18,19}$ There are almost no reports linking cognitive reserve to amelioration of bvFTD. Premi et al. reported that bvFTD patients with higher education harbour worse frontotemporal hypoperfusion than bvFTD patients at the same level of symptom severity but with lower education (less than five years). ${ }^{20}$ Despite having worse brain physiological function, the more highly educated group had no worse disinhibition scores, raising the possibility that they were better able to compensate for severity of brain physiology. ${ }^{20}$ Our results also suggest that behavioural disturbance, and not only cognition, might be influenced by reserve mechanisms.

Initial NPI-apathy scores for both bvFTD and AD were significant predictors of subsequent ROC on the same subscale. That high initial NPI-apathy scores were followed by decreases over time runs counter to our original hypothesis that apathy would predominate in later stages of bvFTD. Others have reported that patients with bvFTD present with either primarily disinhibited or apathetic behaviours, ${ }^{21,22}$ but we have shown in this and in another dataset that disinhibition and apathy co-occur. ${ }^{23}$ If anything, the current samples showed a wider range of apathy scores than of disinhibition. We must revise our hypothesis to accommodate a lessening in apathy over the course of illness, as opposed to an exchange of disinhibition for apathy.

From our comparisons, the FBI was no more revealing for longitudinal observation of BPSD in bvFTD than the NPI. Arguably, the lack of Pearson correlates between NPIdisinhibition and duration of illness in $\mathrm{AD}$ might indicate that the FBI would be the better inventory for tracking disinhibition in $\mathrm{AD}$, but our linear regression for total and subscale scores did not conclude that the FBI as a whole held more statistical significance.

Limitations of our study introduced some degrees of bias and imprecision. Initial assessments were not performed at the onset of symptoms and therefore the data were not ideally collected. The observation epochs are heterogeneous among participants within each diagnostic group. We have tried to minimize this bias by converting the data into annualized ROC but this costs us some precision. In addition, the study recruitment from a convenience sample creates a cross-sectional approach to the longitudinal follow-up. There may be both bias and imprecision inherent to this limitation.
Another bias in our current convenience sample leads us away from being able to test the hypothesis that PPA participants would show an inflection in their behavioural disturbances. By definition, there is a minimum two-year delay of behavioural disturbances after onset of aphasia in PPA. ${ }^{24}$ This would push any observable climb and descent of disinhibition and apathy to a time frame beyond the sixth year originally observed ${ }^{4}$ and the epochs observed for the current PPA sample.

A further limitation to the precision of our data collection is that informants may have differed for a given participant between annual assessments. As a result, it is possible that behavioural changes were not necessarily captured. However, informants changed for a minority $(20 \%)$ of patients, thereby providing us with predominantly consistent reporting.

Behavioural and psychiatric symptoms of dementia upset patients, caregivers and other household members. The sample of participants available to us demonstrated general increases in apathy and disinhibition over the first six to seven years of illness. This increase occurred despite patients being treated at the Clinic, raising questions about the efficacy of treatment or the possibility of apathy having an iatrogenic cause.

We intend to continue the study protocol, in hopes of ultimately answering our question about the inflection in trajectory: revisions to the protocol at this point may be to hone the cohort to be more homogeneous in their duration of illness, i.e., to continue with only those participants for whom we can capture years four to ten of illness.

\section{ACKNOWLEDGMENTS}

The authors thank Andrijana Dzever (University of Toronto Family Medicine), David Fam (University of Toronto Neurology), Jonathan Fridhandler (University of British Columbia Neurology), Noam Grysman (York University), Laura Shnall (Western University) and Mamie Shum (McGill University) for contributing to the data collection in this study.

The authors thank the Sam and Ida Ross Memory Clinic at Baycrest Hospital, the Women of Baycrest, and the Gordie and Colleen Howe Dementia Research Fund for financial support.

\section{Disclosures}

This work (Tiffany Chow) was funded by the Sam and Ida Ross Memory Clinic, the Women of Baycrest, the Gordie and Colleen Howe Dementia Research Fund, and Déanne and Vahram Sedef. Morris Freedman receives support from the Saul A. Silverman Family Foundation as a Canada International Scientific Exchange Program and Morris Kerzner Memorial Fund. Alexandra Linds, Alana Kirstein, Uri Wolf, and Nicolaas PLG Verhoeff report no disclosures.

\section{Statement of Authorship}

$A B$ Linds was the primary author of this manuscript. $A B$ Kirstein participated in data collection, literature search, analysis of the data and was responsible for drafting early versions of the manuscript. M Freedman, NPLG Verhoeff and U Wolf contributed participants and helped to revise and finalize the manuscript. TW Chow participated in the design of the study, contributed patients, supervised acquisition, analysis and interpretation of data, writing and finalization of the manuscript. 


\section{REFERENCES}

1. Mariani C, Defendi S, Mailland E, Pomati S. Frontotemporal dementia. Neurol Sci. 2006;27(Suppl 1):S35-6.

2. Grossman M. Primary progressive aphasia: clinicopathological correlations. Nat Rev Neurol. 2010;6:88-97.

3. Kertesz A, McMonagle P, Blair M, Davidson W, Munoz DG. The evolution and pathology of frontotemporal dementia. Brain. 2005;128:1996-2005.

4. Chow TW, Fridhandler JD, Binns MA, et al. Trajectories of behavioral disturbance in dementia. J Alzheimers Dis. 2012;31:143-9.

5. Benoit M, Dygai I, Migneco O, et al. Behavioral and psychological symptoms in Alzheimer's disease. Relation between apathy and regional cerebral perfusion. Dement Geriatr Cogn Disord. 1999;10:511-7.

6. Chow TW, Binns MA, Cummings JL, et al. Apathy symptom profile and behavioral associations in frontotemporal dementia vs. Alzheimer's disease. Arch Neurol. 2009;66:888-93.

7. Kertesz A, Nadkarni N, Davidson W, Thomas AW. The Frontal Behavioral Inventory in the differential diagnosis of frontotemporal dementia. J Int Neuropsychol Soc. 2000;6:460-8.

8. Neary D, Snowden JS, Gustafson L, et al. Frontotemporal lobar degeneration: a consensus on clinical diagnostic criteria. Neurology. 1998;51:1546-54.

9. McKhann G, Drachman D, Folstein M, Katzman R, Price D, Stadlan EM. Mental and clinical diagnosis of Alzheimer's disease: report of the NINCDS-ADRDA Work Group under the auspices of the Department of Health and Human Services Task Force on Alzheimer's Disease. Neurology. 1984;34:939-44.

10. Crockett DT H, Koch W, Parks R. The Assessment of Everyday Functioning Using the Present Functioning Questionnaire and the functional Rating Scale in Elderly Samples. Clin Gerontol. 1989;8:3-25.

11. Morris J. The Clinical Dementia Rating (CDR): current version and scoring rules. Neurology. 1993;43:2412-4.
12. Knopman DS, Kramer JH, Boeve BF, et al. Development of methodology for conducting clinical trials in frontotemporal lobar degeneration. Brain. 2008;131:2957-68.

13. Cummings JL, Mega M, Gray K, Rosenberg-Thompson S, Carusi DA, Gornbein J. The Neuropsychiatric Inventory: comprehensive assessment of psychopathology in dementia. Neurology. 1994;44:2308-14.

14. Ratnavalli E, Brayne C, Dawson K, Hodges JR. The prevalence of frontotemporal dementia. Neurology. 2002;58:1615-21.

15. Rogalski EM, MM. Clinical Trajectories and Biological Features of Primary Progressive Aphasia (PPA). Curr Alzheimer Res. 2009;6:331-6.

16. Stern Y. What is cognitive reserve? Theory and research application of the reserve concept. J Int Neuropsychol Soc. 2002;8:448-60.

17. Woods B, Aquirre E, Spector AE, Orrell M. Cognitive stimulation to improve cognitive functioning in people with dementia. The Cochrane Review. 2012;2:1-78.

18. Stern Y. Cognitive reserve in ageing and Alzheimer's disease. Lancet Neurol. 2012;11:1006-12.

19. Snowdon DA, Greiner LH, Mortimer JA, Riley KP, Greiner PA, Markesbery WR. Brain infarction and the clinical expression of Alzheimer disease. The Nun Study. JAMA. 1997;277:813-7.

20. Premi E, Garibotti V, Gazzina S, et al. Beyond cognitive reserve: Behavioural reserve hypothesis in Frontotemporal Dementia. Behav Brain Res. 2013;245:58-62.

21. Rascovsky K, Hodges JR, Knopman D, et al. Sensitivity of revised diagnostic criteria for the behavioural variant of frontotemporal dementia. Brain. 2011;134:2456-77.

22. Le Ber I, Guedj E. Gabelle A, et al. Demographic, neurological and behavioural characteristics and brain perfusion SPECT in frontal variant of frontotemporal dementia. Brain. 2006;129:3051-65.

23. Chow TW, Binns MA, Cummings JL, et al. Apathy symptom profile and behavioral associations in frontotemporal dementia vs dementia of Alzheimer type. Arch Neurol. 2009;66:888-93.

24. Mesulam MM. Primary progressive aphasia. Ann Neurol. 2001;49:425-32. 